\title{
Characterization of nanocrystallised multilayered metallic materials produced by the SMAT followed by constrained compression
}

\author{
Szymon Bajda ${ }^{1}$, Stanisław Dymek ${ }^{1}$, Michal Krzyzanowski ${ }^{1,2}$, Delphine Retraint ${ }^{3}$, Janusz \\ Majta $^{1}$, Łukasz Lisiecki ${ }^{1}$, Marcin Kwiecień ${ }^{1}$
}

${ }^{1}$ AGH University of Science and Technology, Mickiewicza 30, Krakow 30-059, Poland

${ }^{2}$ Birmingham City University, Faculty Computing, Engineering \& the Built Environment, Millenium Point, Curzon Street, Birmingham B4 7XG, UK

${ }^{3}$ University of Technology of Troyes, Physics, Mechanics, Material and Nanotechnology Department ICD/LASMIS, CNRS, 12 rue Marie Curie, 10004 Troyes Cedex, France

Corresponding author: Szymon Bajda, e-mail: sbajda@agh.edu.pl

\begin{abstract}
Nanocrystallised multilayered metallic material was obtained via duplex technique combining the surface mechanical attrition treatment (SMAT) with a novel constrained compression (CC) process. At the initial stage the $1 \mathrm{~mm}$ thick sheets of 316L austenitic stainless steel were processed by the SMAT in order to form a nanocrystalline structure. At the final stage discshaped plates excised from SMATed sheets, were assembled in a package and compressed in order to produce metallurgical bonding between individual plates. The characterization of such a multilayered structure was studied both experimentally and numerically. The microscopic examination revealed that the bonding occurred in the central portions of the package where the oxide scale covering each plate was fragmented by high shear strains. The numerical analysis confirmed that the strains at the interior interfaces are significantly higher than at the external ones. A high degree of structural inhomogeneity was observed via TEM studies in the regions where the successful bonding was achieved. Regions characterised by fine band structure with the presence of $\alpha^{\prime}$-martensite phase as well as coarse cellular structure within a single $\gamma$-austenite phase were identified.
\end{abstract}

\section{Keywords:}

SMAT, constrained compression, duplex technique, nanocrystallised multilayered materials, oxidation, finite element analysis

\section{Introduction}

An outstanding improvement of mechanical strength in metallic materials can be achieved through refining of their grain size. Hence, nanocrystallised and ultrafine-grained metals and alloys have been extensively studied over the past decades [1-4]. However, such materials exhibit significantly lower plasticity than their traditional coarse-grained counterparts $[5,6]$.

In order to achieve high mechanical strength with acceptable plasticity simultaneously, the ultrasonic-assisted surface mechanical attrition treatment (SMAT) can be applied $[7,8]$. However, the SMAT allows for refining of the grain size only at the surface layer that extends to the depth of up to several dozen micrometres, preserving the ductility of the core [9-11]. Thus, the SMAT alone is insufficient to improve mechanical strength of bulk materials. To obtain desirable properties, the thickness of a sample has to be on the order of $1 \mathrm{~mm}$, the value that ensures to achieve a reasonable volume fraction of the material strengthened by SMAT to the unaffected material [12]. Such a restricted plate thickness significantly limits the potential application of the SMAT. However, this problem may be overcome by combining the nanocrystallised plates produced by the SMAT into multilayered metallic structures of any 
desirable thickness which make it possible to produce a bulk metallic material with enhanced yield and ultimate strengths while conserving an acceptable elongation to failure. The nanocrystallised plates can be bonded together by any relevant thermo-mechanical process, e.g., accumulative roll bonding (ARB) [13-16].

Before the second step of such a duplex technique combining SMAT with a joining process, a package of plates is heated up to elevated temperature in order to facilitate bonding at their interfaces [13]. Unfortunately, during heating the surfaces of the plates cover by oxide layers that influence bonding mechanisms at the joining step [17]. The oxide layer may remain continuous or may break into fragments allowing for the extrusion of unoxidised metal through appearing gaps within the oxide scale [18]. This fragmentation leads to the establishment of direct contacts between virgin metal surfaces resulting in successful bonding [19]. However, the fragmented oxides on the plate interfaces affect the material flow during joining and thus influence the microstructure development in their proximity. The mentioned phenomenon can also have an impact on the final material properties [20,21].

In this work, plates after SMAT were joined together by applying a constrained compression (CC). This novel $\mathrm{CC}$ technique may be considered as a foundation for development of a relevant combined thermo-mechanical process leading towards processing of structural multilayered metallic materials. Microstructural studies using optical microscopy (OM), scanning electron microscopy (SEM) and transmission electron microscopy (TEM) were conducted to characterise the microstructure of AISI 316L stainless steel processed by combination of the SMAT and CC techniques. Additionally, finite element (FE) analysis was performed in order to identify zones of high strain localization near the plate interfaces.

\section{Experimental}

The investigation was performed on an AISI 316L austenitic stainless steel with initial grain size of 10-50 $\mu \mathrm{m}$ and chemical composition given in Table 1 .

Table 1 AISI 316L austenitic stainless steel chemical composition (wt\%).

\begin{tabular}{|c|c|c|c|c|c|c|c|c|c|}
\hline Fe & $\mathrm{C}$ & $\mathrm{Si}$ & $\mathrm{Mn}$ & $\mathrm{P}$ & $\mathrm{S}$ & $\mathrm{Cr}$ & $\mathrm{Mo}$ & $\mathrm{Ni}$ & $\mathrm{N}$ \\
\hline bal. & 0.02 & 0.488 & 0.90 & 0.0315 & 0.0002 & 16.998 & 2.03 & 11.039 & 0.0287 \\
\hline
\end{tabular}

In the first stage, cold rolled, $1 \mathrm{~mm}$ thick sheets were subjected to the SMAT. The process was conducted in air at room temperature for 30 minutes. The attrition was performed with $3 \mathrm{~mm} 100 \mathrm{Cr} 6$ steel balls, at a vibration frequency of $20 \mathrm{kHz}$ as described in Ref. [12]. In the following stage, eight disc-shaped plates of $10 \mathrm{~mm}$ diameter were excised from SMATed sheets by a waterjet, degreased with acetone and scratch-brushed. Subsequently, the discs were placed in a specially designed hollow die, responsible for the improvement of the mechanical conditions at the plates interfaces allowing for successful bonding between particular plates during thermo-mechanical processing [22]. The hollow die of $8 \mathrm{~mm}$ thickness, $30 \mathrm{~mm}$ outer diameter and a $10 \mathrm{~mm}$ in diameter hole was laser machined from a coarse-grained $316 \mathrm{~L}$ stainless steel. Thereafter, such a package of discs inserted into the hollow die was annealed at $550{ }^{\circ} \mathrm{C}$ for 30 minutes and compressed up to $70 \%$ reduction, between the specially developed rounded anvils, warmed up to about $200{ }^{\circ} \mathrm{C}$. This relatively high reduction was reached at the centre of the package, where the greatest level of deformation was achieved. 
a)

b)

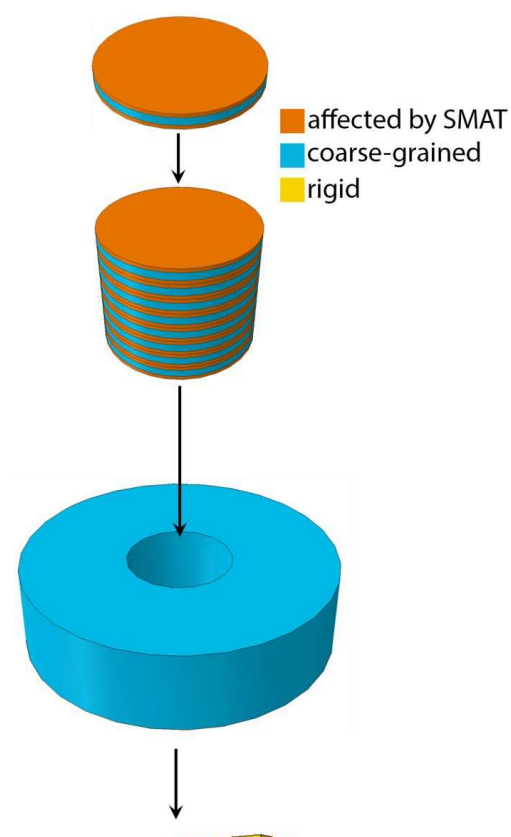

d)

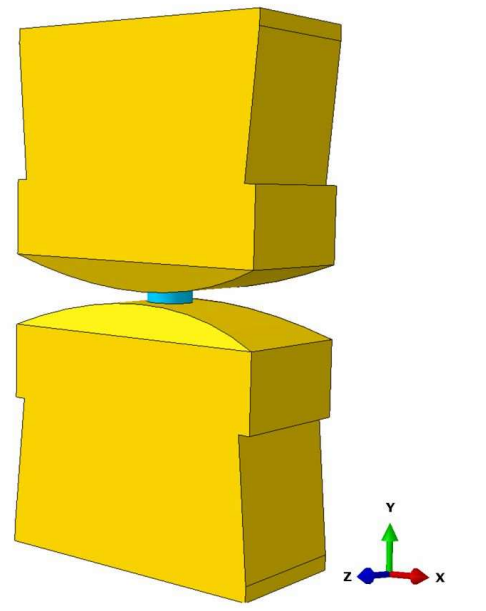

Fig. 1 Schematic representation of the CC process: a) single SMATed plate, b) package of eight SMATed plates, c) hollow die, d) die with package placed between rounded shape tools.

The schematic set-up of the CC process is presented in Fig. 1, while the image of the compression rig is shown in Fig. 2. The hydraulic press of $5000 \mathrm{kN}$ capacity was. The speed of the top anvil was $7 \mathrm{~mm} / \mathrm{s}$, while the bottom one was fixed. The tool radius was $250 \mathrm{~mm}$ and its shape allowed the generation of the relevant shearing necessary for the successful bonding at the plate interfaces [23]. Moreover, such a tool shape allowed to achieve higher reduction levels comparing with the conventional forging realised on the same press. 


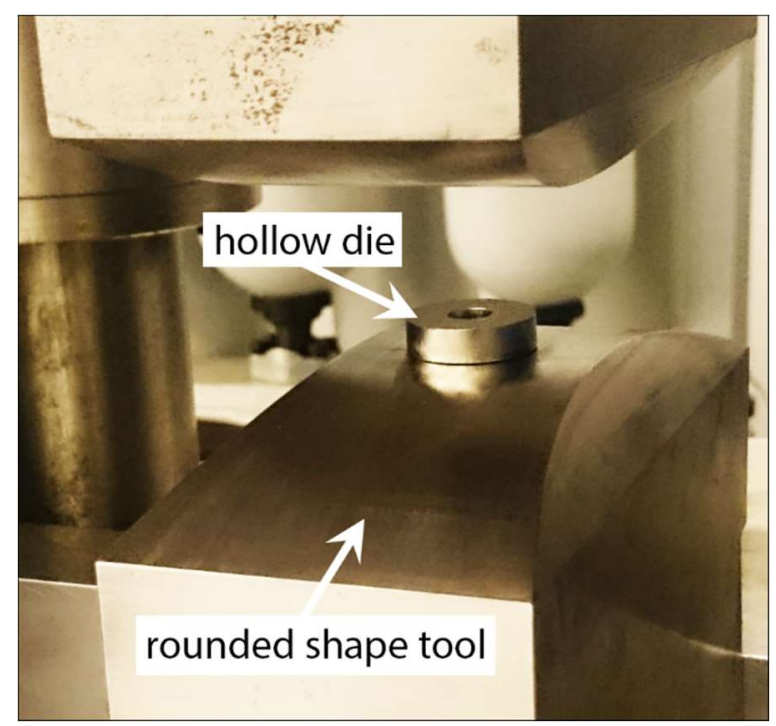

Fig. 2 CC processing set-up.

The OM as well as SEM and TEM examination was performed on the sample crosssections. The samples for TEM studies were excised by the Focused Ion Beam (FIB) technique.

Hardness measurements were also conducted on the sample cross-sections using a Vickers microhardness tester with $25 \mathrm{~g}$ indentation load and $15 \mathrm{~s}$ dwell time. Three indentations were applied at the same depths from the surface and the results were averaged. A distance between two neighbouring indentations was established to at least $25 \mu \mathrm{m}$ in order to prevent inaccurate measurements resulted from the affected plastic zone in the vicinity of an indent.

\section{Results and discussion}

\subsection{Microscopic examination}

The preparation of the oxidised specimens for microscopic investigation is extremely difficult due to hardness and brittleness of the oxide scale. The interfacial decohesion of the oxide scale from the metal is often observed, whereas the adhesion between the resin and oxides is preserved [28]. In the cases, where there is no contact between the resin and oxide scale, as it was in this study, the interfacial decohesion can easily occur from both sides of the scale resulting in spallation of the scale fragments leaving gaps. The gaps at the interfaces left from the spalled oxides can be observed in SEM images (Fig. 3d and 4a). While SEM micrographs confirming the presence of the oxides together with qualitative compositional analyses performed using energy-dispersive X-ray spectroscopy (EDS) were added to data repository.

The microstructures after SMAT processing are characterised by a great number of aligned deformation bands reaching the depth about $100 \mu \mathrm{m}$ below the surface (Fig. 3a). The presence of these bands and a small distance between them (less than $1 \mu \mathrm{m}$ ) indicates deformation strengthening occurring during the SMAT [24]. The previous investigation showed that the same steel $(316 \mathrm{~L})$ contained about $13 \%$ vol. strain induced $\alpha^{\prime}$-martensite phase after the SMAT processing [12]. The presence of $\alpha^{\prime}$-martensite phase has a significant impact on ductility of steels and increases the work-hardening capacity resulting in enhanced strength and formability [25-27].

The 30 minutes annealing caused formation of the oxide scale layer on SMATed surfaces of the discs placed within a hollow die. The X-ray diffraction (XRD) surface analysis of individual SMATed sheets from the same material annealed at the same $550{ }^{\circ} \mathrm{C}$ temperature 
during 30 minute period of time revealed 10 to $20 \%$ volume fraction of $\mathrm{Fe}_{2} \mathrm{O}_{3}$ and 1 to $2 \%$ of $\mathrm{Fe}_{3} \mathrm{O}_{4}$ on average up to $7 \mu \mathrm{m}$ below the surface [12]. A comparable study after the $\mathrm{CC}$ processing was not possible to perform as only the cross-section of the sample was examined. However, the CC lasted less than 1 second, which is negligible comparing to the oxidation time during the annealing stage. It allows for assumption that the oxide scale formed near the interfaces in the package of plates is similar to the one grown at the surfaces of the individual plates annealed outside the hollow die.
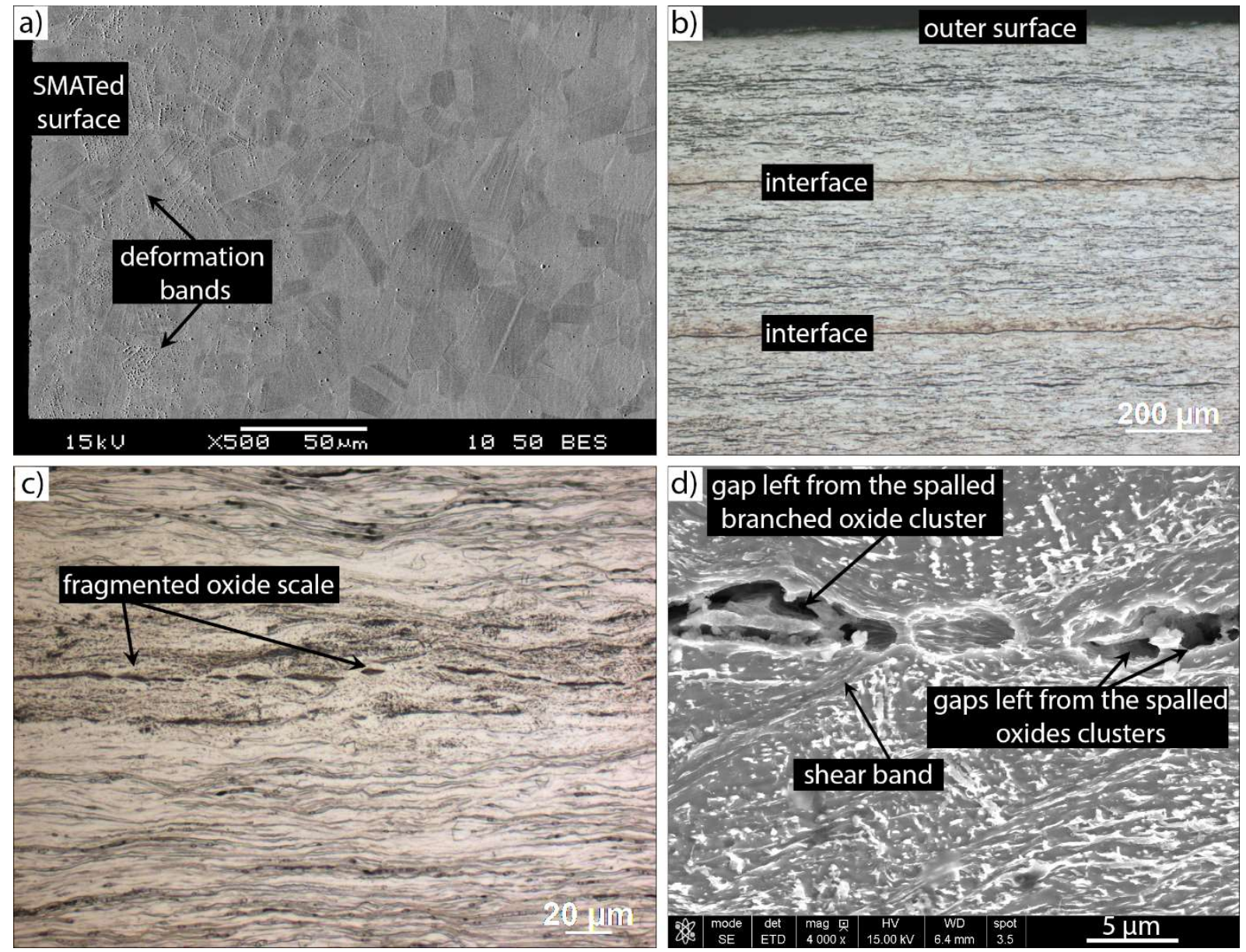

Fig. 3 Optical ( $b$ and $c$ ) and SEM ( $a$ and d) images showing $a$ ) the cross-section microstructure of the sheet after SMAT, $b$ ) interfaces between plates with continuous oxide scale layer, $c, d)$ interface between bonded plates with cracked oxide scale layer.

There were seven interfaces in the package of plates in total. It was observed that there is a continuous oxide scale layer on the two most external ones (Fig. 3b), whereas fragmented oxide scale layers were recognized on all three middlemost interfaces. The microstructure shown in Fig. 3c indicates, that the oxide scale layer of a few micrometres thick cracked during the joining stage of the duplex technique allowing for the extrusion of the unoxidised metal through arising gaps and thus forming a reliable joint between two individual plates. The oxide scale can behave in a brittle or ductile manner depending on the deformation temperature [29]. It was shown that for the ARB processing of nanocrystalline $316 \mathrm{~L}$ stainless steel plates, the layer breaks at $550{ }^{\circ} \mathrm{C}$, whereas at $650{ }^{\circ} \mathrm{C}$, it remains continuous [18]. The $\mathrm{CC}$ processing performed at $550{ }^{\circ} \mathrm{C}$ confirmed cracking of the oxide scale at inner interfaces. The presence of a continuous oxide layer at the outer interfaces, despite the temperature of $550{ }^{\circ} \mathrm{C}$, may be explained by relatively low strain, and thus not sufficient shear bands generation, in those areas since the other phenomenon responsible for the fracturing is shear banding [30-33]. The oxide 
scale can break due to the activation of two different forms of shear bands. First, typical shear bands, which give rise to fracturing of the oxide scale layer into separate clusters allowing for the formation of metal-metal joint between them (Fig. 3d). Second, branched shear bands, which are regarded as the main cause of so-called "river lines" in rolled metallic materials [34]. "River lines" were recently observed in roll bonded aluminium [23] and titanium [35] strips. Although the shear bands of the second type are not clearly visible in SEM micrographs, it was proved by Quadir et al. [23] that their presence may cause penetration of the oxide cluster followed by filling its interior with surrounding material, which was also observed in Fig. $3 \mathrm{~d}$. This phenomenon helps to decompose the oxide scale and at higher degree of deformation, for example in multiple cycles of ARB, the formation of shear bands become more intense additionally improving the bond strength between metallic layers $[23,36]$. Shear banding in refined microstructures is even more frequent as deformation involves fine grains [37]. Hence, it should occur more easily during the $\mathrm{CC}$ deformation at the interfaces of the materials in which surfaces were earlier affected by SMAT, supporting the fragmentation of oxide scale layers. The localization of plastic deformation into shear bands was reported in many nanocrystalline materials, e.g. in steel [38-40], iron [41-44], copper [45,46] and nickel [47,48]. Another factor enhancing the joint quality is local adiabatic heating deriving from great amounts of plastic deformation localized in shear bands that boost atomic movements at the metallic interface.

Oxide clusters formed at the interface disturb the material flow in their neighbourhood (Fig. 3d). It may affect the final properties of nanocrystallised multilayered metallic materials. Similar phenomenon has been observed during another duplex treatment, in which ARB was used as a joining step [18]. Moreover, it was proved that there is a significant inhomogeneity in microstructure, including different volume fractions of $\alpha^{\prime}$-martensite phase, originated during SMAT processing, which additionally complicates the prediction of material behaviour [12]. 

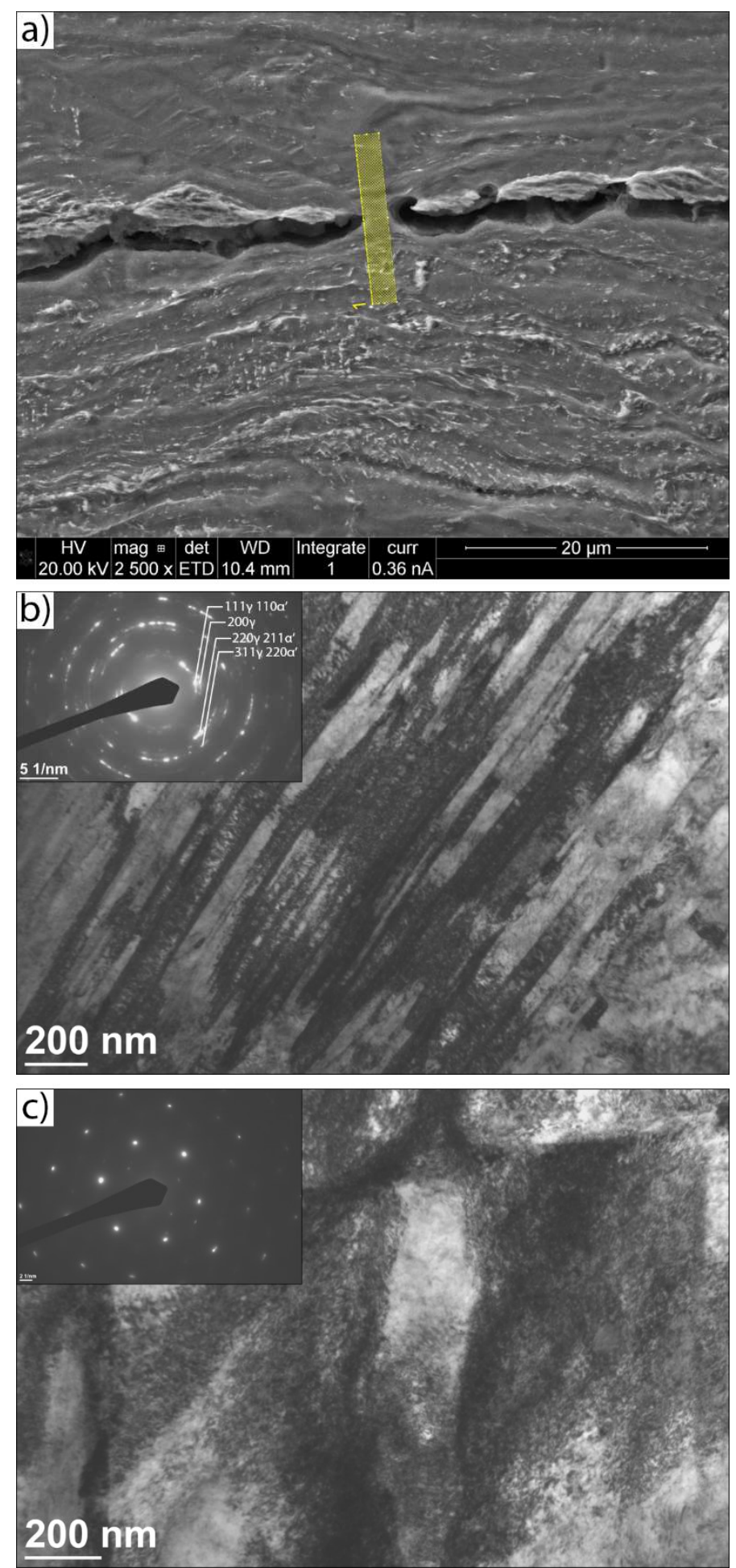

Fig. 4 SEM (a) and TEM (b and c) bright-field micrographs showing a) the cross-section of the interface between bonded plates from which a thin foil for TEM studies was prepared, $b$, c) the dislocation substructure region showing the effect of relatively high (b) and low (c) plastic deformation.

For deeper understanding of microstructural changes at the plates interfaces, TEM observations were performed. FIB technique was employed for preparation of the thin foil from the area in which successful bonding between metallic plates was obtained (Fig. 4a, rectangle marked in yellow). The microstructure shown in Fig. 4b is greatly refined, as evidenced by the presence of many rings in the selected area electron diffraction (SAED) pattern. A high 
dislocation density indicates, that recrystallization did not occur in this region. Dislocations are arranged into planar arrays, which is typical for the fcc materials with low stacking-fault energy (SFE) subjected to plastic deformation. Such an arrangement into planar arrays occurs on their primary slip planes due to low values of SFE, which makes the partial dislocations cross-slip difficult [49]. The SAED pattern revealed existence of two phases, which confirms that CC processing at $550{ }^{\circ} \mathrm{C}$ preserved the $\alpha^{\prime}$-martensite phase. Moreover, it was shown in previous work using Rietveld analysis, that the volume fraction of $\alpha^{\prime}$-martensite increases significantly after annealing at even higher temperatures [12]. Roland et al. observed similar phenomenon for SMATed 316L stainless steel [50]. They annealed samples for 10 minutes at 200, 300 and $500{ }^{\circ} \mathrm{C}$ and noticed an increase in the amount of $\alpha^{\prime}$-martensite of about 13, 47 and $67 \%$ respectively. Such a phenomenon can be explained by the local increase of $\mathrm{M}_{\mathrm{s}}$ (martensite start) temperature in areas depleted in alloying elements due to inhomogeneous chemical composition resulted from the applied heat treatment. During annealing, the $\alpha^{\prime}$-martensite phase is progressively transformed to austenite, however during the cooling to room temperature, the $\alpha^{\prime}$-martensite volume fraction increases again [51]. When CC process began, the sample was already after 30 minutes of annealing, hence the volume fraction of $\alpha^{\prime}$-martensite was reduced. The compression was applied before the cooling step, which undoubtedly influenced the above mentioned phase transformation mechanism. Furthermore, the cooling rate was significantly higher due to the contact of the sample with tools. Moreover, the greatly refined microstructure after the SMAT processing additionally affects $\gamma \rightarrow \alpha^{\prime}$ transformation. Jung et al. showed [52], that the strain-induced martensite start $\mathrm{M}_{\mathrm{d}}$ temperature decreases with grain size reduction below $1 \mu \mathrm{m}$ for metastable austenitic steel. Nohara et al. [53] studied the effect of initial austenite grain size on the temperature, at which $50 \%$ of the austenite transforms to martensite phase with $30 \%$ true strain $\mathrm{M}_{\mathrm{d} 30}$. They noticed that the volume fraction of strain induced $\alpha^{\prime}-$ martensite decreases and the value of $\mathrm{M}_{\mathrm{d} 30}$ reduces with decreasing the grain size. In contrary, Shrinivas et al. [54] revealed a lack of influence of refined grain size on $\alpha^{\prime}$-martensite volume fraction for AISI 316 stainless steel, whereas the amount of $\alpha^{\prime}$-martensite increased for AISI 304 alloy. Lee et al. [55] observed lowering of $M_{s}$ temperature with decreasing the grain size for low alloy steel. They also examined the kinetics of martensitic transformation and noticed that it is affected by the austenite grain size. The area from which a thin foil was prepared was relatively small (Fig. 4a). However two micrographs obtained from this region are characterised by totally different microstructures. While the first one (Fig. 4b) is characterised by a fine band structure with a SAED pattern that indicates the presence of $\alpha^{\prime}$-martensite and austenite phases, the other one (Fig. 4c) is represented by a relatively coarser cellular structure and only one single phase, $\gamma$-austenite. Such a high level of inhomogeneity resulting from phenomena described earlier makes the prediction of the $\alpha^{\prime}$-martensite volume fraction very difficult. Furthermore, the relatively small dimensions of the studied area do not permit to perform experimental measurements in order to obtain quantitative data of the phase content.

\subsection{Hardness measurements}

Hardness on the cross-section of SMATed plates bonded through the CC processing was measured using Vickers microhardness tester and the results are presented in Fig. 5. The character of the curve shows that the hardness significantly increases near the interfaces of the joined plates reaching almost $450 \mathrm{HV}$. Measurements were performed up to $1.8 \mathrm{~mm}$ depth and the increased HV values were identified at the four following depths: about 0.5, 0.9, 1.3 and $1.7 \mathrm{~mm}$. These depths correspond well with positions of interfaces observed during $\mathrm{OM}$ analysis (Fig. 6b). 


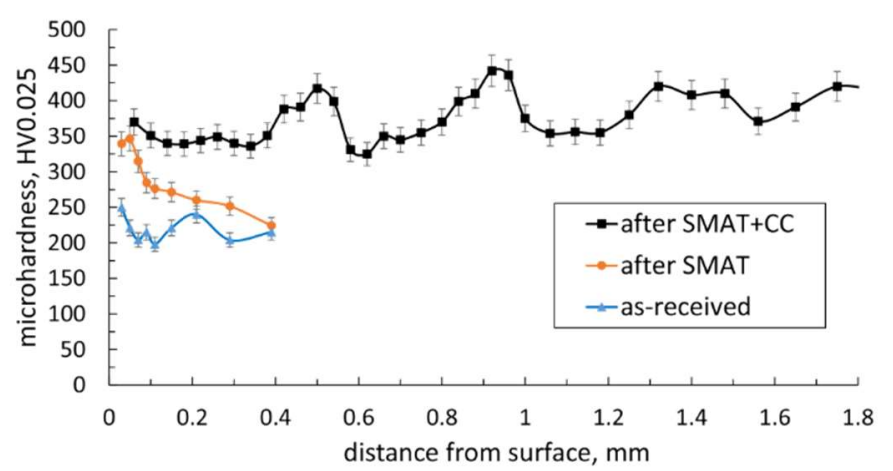

Fig. 5 Cross-sectional Vickers microhardness variations.

Hardness after the SMAT increased to the depth of about $300 \mu \mathrm{m}$ below the plate surface. It means that the core of the plate situated about $400 \mu \mathrm{m}$ below the surface remained unchanged, as in the as-received sample. After the CC processing, the HV values increased significantly accross the entire depth of the plate indicating the strengthening of the whole sample located in the hollow die. Moreover, after the CC processing, hardness of the areas unaffected by the SMAT increased or even surpassed hardness of the surface subjected to only the SMAT.

\subsection{Numerical analysis}

The purpose of the numerical analysis was to identify zones of high strain localizations near the plate interfaces at the macro scale. The oxidised surface layers was not considered in the analysis, as the thickness of the formed oxide scale is relatively small comparing to the thickness of the metallic plates making influence of the oxides on the level of the resulted strains negligible. Moreover, coupling of the relatively small features, such as oxide scales of different morphology, with a macro model can cause serious numerical difficulties.

A 3D FE based thermo-mechanical model was developed and applied for the analysis using Abaqus software (Fig. 1). A single plate with $1 \mathrm{~mm}$ thickness and $10 \mathrm{~mm}$ diameter was modelled (Fig. 1a). The experimental results indicated that the SMAT caused increase of the hardness below the material surface up to the depth of about 250-300 $\mu \mathrm{m}$ (Fig. 5). This finding corresponds well with the results of Waltz et al. [56] who observed, through nanoindentation tests, that the hardness increases up to the depth of about $250 \mu \mathrm{m}$ for the same $316 \mathrm{~L}$ stainless steel and for the identical SMAT parameters. The thickness of the SMATed layer in the model was assumed to be $250 \mu \mathrm{m}$. Hence, a single plate of one $500 \mu \mathrm{m}$ thick coarse-grained layer in the core and two $250 \mu \mathrm{m}$ thick layers outward was taken into account. The hardness gradient through the thickness of the SMATed sample was rather high. Hence, it was desirable to assign different stress-strain curves at various depths below the SMATed surface. Thus, each SMATed outward layer was divided into five sublayers, each having $50 \mu \mathrm{m}$ thickness.

The flow stress for coarse-grained material $\sigma_{c}$ during the $\mathrm{CC}$ processing at elevated temperatures was introduced as a function of temperature $T$ and equivalent strain $\varepsilon[20,21]$ :

$$
\sigma_{c}=335+1255 \varepsilon^{0.733}-0.095 T^{1.1}
$$

It was shown that the flow stress $\sigma$ can be related to hardness $H_{V}$ by the following equation $[57,58]$ :

$$
\sigma=c H_{V}
$$


where $c$ is a parameter depending on the strain, $\sigma$ is expressed in MPa and $H_{V}$ in $\mathrm{kg} f / \mathrm{mm}^{2}$. Assuming that the parameter $c$ is the same for coarse-grained and SMATed material, the function $F(x)$ was developed:

$$
F(x)=\frac{H_{V_{S M A T(x)}}}{H_{V_{c}}}
$$

where $H_{V_{S M A T}}$ is the hardness of SMATed material, $H_{V_{c}}$ is the hardness of coarse-grained material and $x$ is the sublayer number. The hardness measurements carried out below the SMATed surface (Fig. 5) were used to develop the flow stress for each sublayer affected by SMAT $\sigma_{S M A T}(x)$ utilizing equations (1) and (3):

$$
\sigma_{S M A T(x)}=F(x) \cdot \sigma_{c}
$$

Roland et al. [50] proved that the nanocrystalline layer of AISI 316L stainless steel is stable during annealing treatment up to $600{ }^{\circ} \mathrm{C}$, thus the above equation should be valid below this threshold.

All other properties were assumed to be identical for both materials as there is no data available in the literature regarding appropriate characteristics of the $316 \mathrm{~L}$ stainless steel with refined grain structure (Table 1).

Table 1 Properties of 316L stainless steel used in the numerical analysis [59].

\begin{tabular}{|c|c|}
\hline Property & Value \\
\hline Density, $\mathrm{kg} / \mathrm{m}^{3}$ & $\rho(T)=7921-0.614 T+0.0002 T^{2}$ \\
\hline Specific Heat, $\mathrm{J} /(\mathrm{kg} \mathrm{K})$ & $c_{p}(T)=440.79+0.5807 T-0.001 T^{2}+7 \cdot 10^{-7} T^{3}$ \\
\hline Thermal Conductivity, W/(mK) & $\lambda(T)=14.307+0.0181 T-6 \cdot 10^{-6} T^{2}$ \\
\hline Young's Modulus, GPa & 193 \\
\hline Poisson's Ratio & 0.3 \\
\hline
\end{tabular}

A package consisting of eight plates placed one over another (Fig. 1b) was inserted into the model of the hollow die (Fig. 1c) and compressed between rigid rounded shape tools (Fig. 1d). It was assumed that the properties of the hollow die were the same as for the coarse-grained AISI 316L stainless steel. The numerical calculations were performed using 60457 elements including 681 10-node modified thermally coupled second-order tetrahedron C3D10MT elements representing tools, 640 8-node thermally coupled brick trilinear displacement and temperature with reduced integration C3D8RT elements representing the hollow die and 59136 C3D8RT elements of the same type representing the package of eight plates. In order to reduce the CPU time required for obtaining the solution, the symmetric boundary conditions were applied allowing for consideration of only a one-eighth of the model.

A standard Coulomb isotropic friction model was used in the numerical analysis. It assumes no relative motion between surfaces, if the equivalent frictional stress $\bar{\tau}$ is less than the critical stress $\tau_{c r}$, which is proportional to the contact pressure as was shown below:

$$
\begin{array}{r}
\bar{\tau}=\sqrt{\tau_{1}^{2}+\tau_{1}^{2}} \\
\tau_{c r}=\min \left(\mu p, \tau_{\max }\right)
\end{array}
$$

where $\mu$ is the friction coefficient, $p$ is the contact pressure and $\tau_{\text {max }}$ is an adjustable parameter. When the equivalent frictional stress reaches the critical stress the slip occurs. The direction of the slip and the frictional stress coincide as follows: 


$$
\frac{\tau_{n}}{\bar{\tau}}=\frac{\dot{\gamma_{n}}}{\bar{\gamma}}
$$

where $\dot{\gamma_{n}}$ is the slip rate in direction $n$ and $\overline{\dot{\gamma}}$ is the equivalent slip velocity:

$$
\overline{\dot{\gamma}}=\sqrt{\gamma_{1}^{2}+\gamma_{2}^{2}}
$$

The condition of no relative motion between contacting surfaces is approximated by stiff elastic behaviour. Hence, the relative motion from the zero shear stress position is bounded by the allowable maximum elastic slip $\gamma_{c r}$, which was set as $0.5 \%$ of the average length off all contact elements. A fixed friction coefficient 0.3 was assumed in the model.

a)
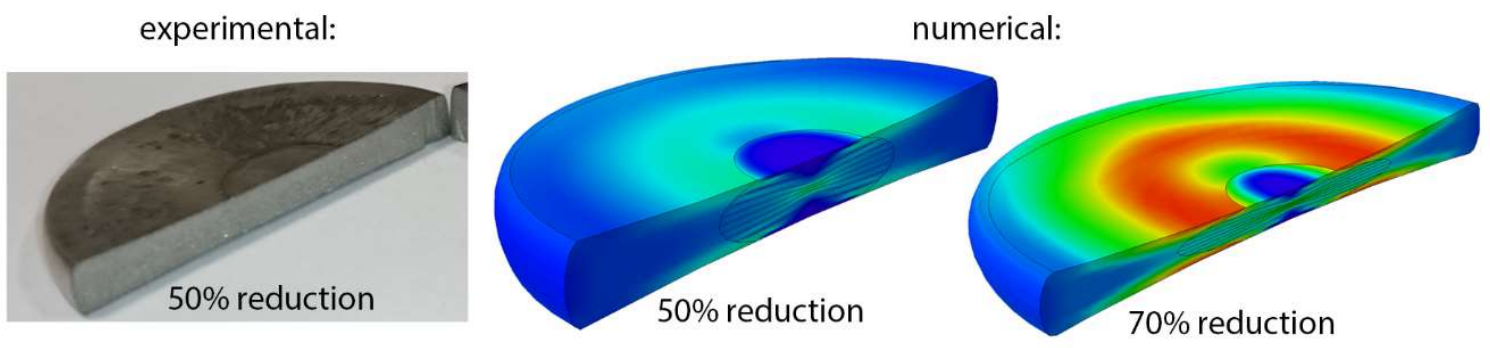

b)

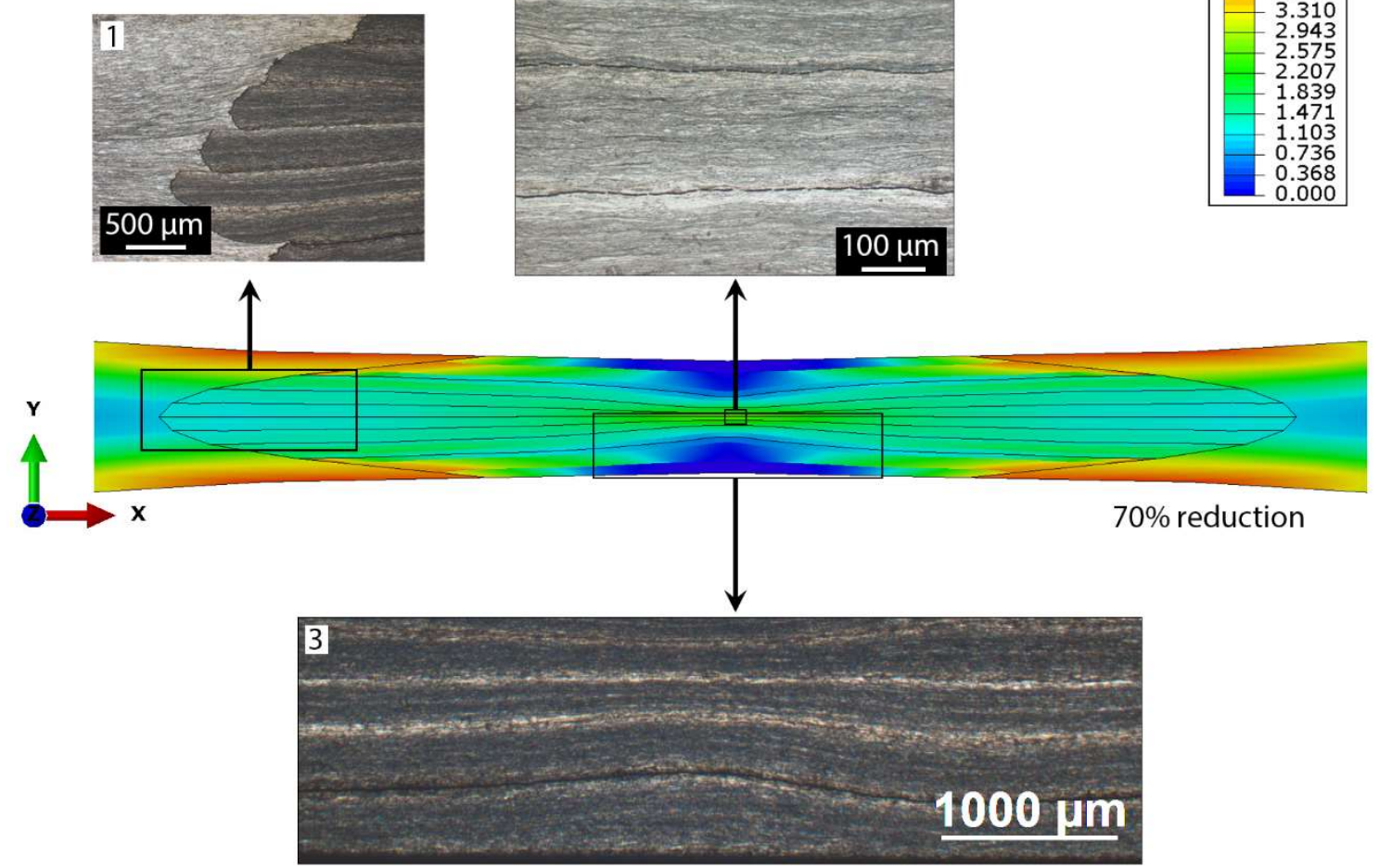

Fig. 6 Numerical results showing distribution of the equivalent strain within the cross-section of the hollow die with package compared with experimental data a) for 50 and $70 \%$ reduction, b) for $70 \%$ reduction at $x$-y plane view with marked zones at which corresponding micrographs have been obtained (marked as 1, 2 and 3). 
Fig. 6 presents the equivalent strain distribution at the cross-section of the package and hollow die in comparison with experimental data. Fig. 6a illustrates the compressed package within hollow die using 50 and $70 \%$ reductions. The characteristic specimen profile with varying thickness, from the lowest at the same centre to the highest at the sides, was predicted numerically and observed experimentally. The influence of the rounded shape tools on deformation of the compressed material is clearly visible especially at its surfaces, where the strains are higher than in the other areas due to the shear stresses resulted from such tool shape. Relatively high strains are also noticeable in the middle of the package volume, where they form a characteristic cross-shaped pattern also observed during conventional forging operations. The lowest deformation is observed in the middle of the surfaces, at the place of the early contact with the tools, and below them. It can be seen (Fig. 6b), that the thickness of the outer plates is significantly greater than the thickness of the interior plates. This effect was also observed experimentally (Fig. 6b-3). The closer to the middle the plate is located within the package, the higher is its reduction and greater is its diameter, which was also confirmed by microscopic studies (Fig. 6b-1).

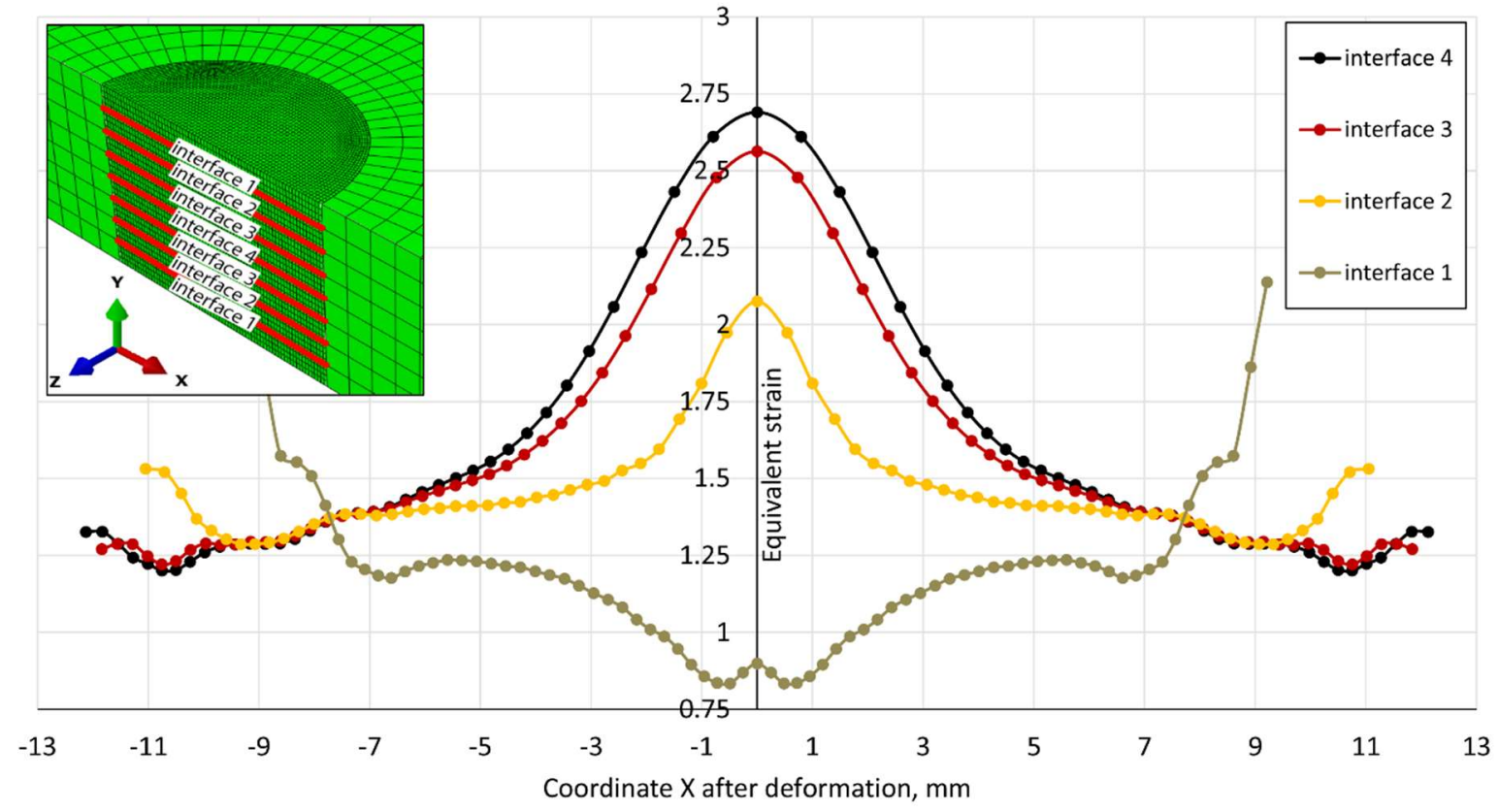

Fig. 7 The equivalent strain predicted at the nodes representing the interfaces between the compressed plates. The model with marked nodes before the compression is shown in the upper left corner.

Fig. 7 shows the equivalent strain predicted at the nodes situated on the plate interfaces after the CC processing. It can be seen that the strain intensity is much larger at the interfaces marked as number 3 and 4, than for the rest of them. Such notable differences can be observed at a distance of up to about $6 \mathrm{~mm}$ from the centre of the package. Experimental investigation proved that the breaking of the oxide scale occurred at the interior interfaces, between third, fourth, fifth and sixth plate, which correspond to the modelled interfaces no. 3 (between third and fourth as well as fifth and sixth plate) and no. 4 (between fourth and fifth plate). Moreover, it was observed on micrographs that the oxide scale layer has not cracked at the outer interfaces marked as number 1 and 2 in Fig. 7. Numerical analysis showed, that the equivalent strain at these areas is significantly lower than the strains developed at the middle of the package. When the distance from the package centre is more than about $7 \mathrm{~mm}$, the equivalent strain at the outer interface 1 is notably increased, which is due to the tensile strains resulted from the interaction of the tools with the material surface (Fig. 6). 


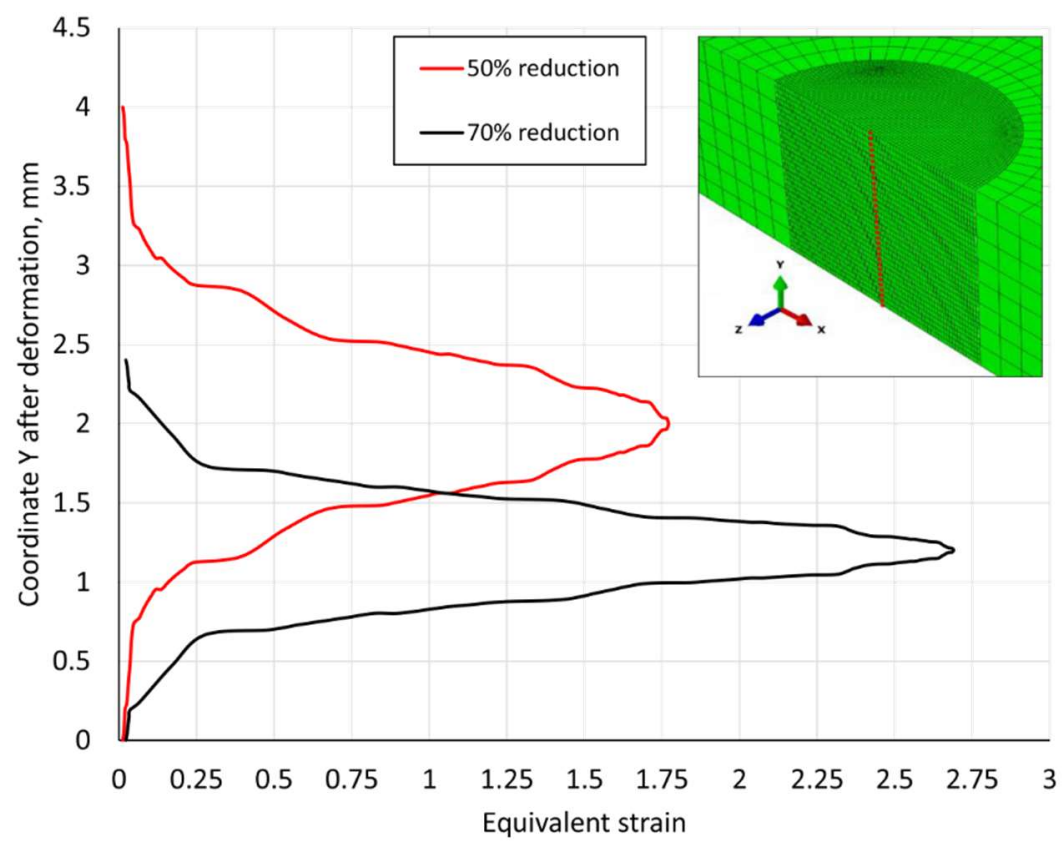

Fig. 8 The equivalent strain predicted at the nodes located across the thickness of the package at its centre. The model before deformation with marked nodes is shown in the upper right corner.

The strain intensity predicted across the thickness of the package at its centre for 50 and $70 \%$ reduction is shown in Fig. 8. There are significant differences in the strain predicted for the mentioned reductions. It was found experimentally that bonding between SMATed plates is established for the case when higher reduction was applied and the breaking of the oxide scale occurred only at the interior interfaces (Fig. 6b-2).

\section{Conclusions}

In the present work, a nanocrystallised multilayered metallic material was successfully processed combining SMAT with a novel CC technique developed by the authors. The behaviour of the obtained material was analysed both experimentally and numerically. Through-thickness cracking of the oxide scale layer was observed at the interior interfaces, whereas continuous oxide layer was identified at the outer ones. TEM studies were performed in the area between the oxide clusters where successful bonding was established. It was found, that this relatively small region is characterised by a high degree of structural inhomogeneity. The TEM micrographs revealed two totally different microstructures. The first microstructure was characterised by fine band structure with the presence of $\alpha^{\prime}$-martensite while the other one was coarse cellular structure within a single phase: $\gamma$-austenite. The numerical analysis of the $\mathrm{CC}$ processing showed that the strains at the interior interfaces are significantly higher than the strains at the nodes representing the outer ones. The noticed effect corresponds to the microstructural observations confirming the presence of the cracked oxide scale layer on the interior and a continuous oxide layer observed on the exterior interface. The optical micrographs of the sample cross-sections confirmed a good agreement between experimental and predicted specimen profiles. 


\section{Acknowledgements}

Research presented in the current work was prepared with the financial support provided by National Science Centre, Poland (grant no. DEC-2013/09/B/ST8/00141). Numerical investigation was performed with the assistance of National Science Centre, Poland (grant no. DEC-2016/21/N/ST8/00091).

\section{Data availability}

The raw data required to reproduce these findings are available to download from DOI: $10.17632 / 5 \mathrm{wdtd} 5 \mathrm{~s} 2 \mathrm{nx}$. 1 . The processed data required to reproduce these findings are available to download from DOI: $10.17632 / x p d v h r 4 d h d .1$.

\section{References}

[1] H. Gleiter, Nanocrystalline materials, Prog. Mater. Sci. 33 (1989) 223-315. doi:10.1016/0079-6425(89)90001-7.

[2] C. Suryanarayana, Nanocrystalline materials, Int. Mater. Rev. 40 (1995) 41-64. doi:10.1179/095066095790151106.

[3] M.A. Meyers, A. Mishra, D.J. Benson, Mechanical properties of nanocrystalline materials, Prog. Mater. Sci. 51 (2006) 427-556. doi:10.1016/j.pmatsci.2005.08.003.

[4] C.C. Koch, Structural nanocrystalline materials: An overview, J. Mater. Sci. 42 (2007) 1403-1414. doi:10.1007/s 10853-006-0609-3.

[5] K. Muszka, J. Majta, P.D. Hodgson, Study of the grain size effect on the deformation behavior of microalloyed steels, in: Proc. Mater. Sci. Technol., Association for Iron and Steel Idustry, Detroit MI, 2007: pp. 493-504.

[6] X.H. Chen, J. Lu, L. Lu, K. Lu, Tensile properties of a nanocrystalline 316L austenitic stainless steel, Scr. Mater. 52 (2005) 1039-1044. doi:10.1016/j.scriptamat.2005.01.023.

[7] K. Lu, J. Lu, Nanostructured surface layer on metallic materials induced by surface mechanical attrition treatment, Mater. Sci. Eng. A. 375-377 (2004) 38-45. doi:10.1016/j.msea.2003.10.261.

[8] Y. Samih, B. Beausir, B. Bolle, T. Grosdidier, In-depth quantitative analysis of the microstructures produced by Surface Mechanical Attrition Treatment ( SMAT), Mater. Charact. 83 (2013) 129-138. doi:10.1016/j.matchar.2013.06.006.

[9] N.R. Tao, Z.B. Wang, W.P. Tong, M.L. Sui, J. Lu, K. Lu, An investigation of surface nanocrystallization mechanism in Fe induced by surface mechanical attrition treatment, Acta Mater. 50 (2002) 4603-4616. doi:10.1016/S1359-6454(02)00310-5.

[10] J. Petit, L. Waltz, G. Montay, D. Retraint, A. Roos, M. François, Multilayer modelling of stainless steel with a nanocrystallised superficial layer, Mater. Sci. Eng. A. 536 (2012) 124-128. doi:10.1016/j.msea.2011.12.085.

[11] G. Liu, J. Lu, K. Lu, Surface nanocrystallization of 316L stainless steel induced by ultrasonic shot peening, Mater. Sci. Eng. A. 286 (2000) 91-95. doi:10.1016/S09215093(00)00686-9.

[12] S. Bajda, W. Ratuszek, M. Krzyzanowski, D. Retraint, Inhomogeneity of plastic deformation in austenitic stainless steel after surface mechanical attrition treatment, Surf. Coatings Technol. (2017). doi:10.1016/j.surfcoat.2017.09.049.

[13] L. Waltz, D. Retraint, A. Roos, P. Olier, Combination of surface nanocrystallization and co-rolling: Creating multilayer nanocrystalline composites, Scr. Mater. 60 (2009) 21-24. doi:10.1016/j.scriptamat.2008.08.024.

[14] Y. Saito, H. Utsunomiya, N. Tsuji, T. Sakai, Novel ultra-high straining process for bulk 
materials - development of the accumulative roll-bonding (ARB) process, Acta Mater. 47 (1999) 579-583. doi:10.1016/S1359-6454(98)00365-6.

[15] Z.. Deng, L.L.. Wang, D.. Zhang, J.. Liu, C.. Liu, J.. Ma, Lanthanum-containing hydroxyapatite coating on ultrafine-grained titanium by micro-arc oxidation: A promising strategy to enhance overall performance of titanium, Med. Sci. Monit. 20 (2014) 163-166. doi:10.12659/MSM.889894.

[16] C.C.F. Kwan, Z. Wang, A composite nature of cyclic strain accommodation mechanisms of accumulative roll bonding (ARB) processed $\mathrm{Cu}$ sheet materials, Mater. Sci. Eng. A. 528 (2011) 2042-2048. doi:10.1016/j.msea.2010.11.018.

[17] D. Retraint, M.Z. Quadir, W.Q. Xu, L. Waltz, M. Ferry, Microstructural Investigation of Co-Rolled Nanocrystalline Stainless Steel Sheets, Mater. Sci. Forum. 702-703 (2011) 127-130. doi:10.4028/www.scientific.net/MSF.702-703.127.

[18] L. Waltz, D. Retraint, A. Roos, C. Garnier, P. Olier, Effect of interfacial oxidation occurring during the duplex process combining surface nanocrystallisation and corolling, Surf. Coatings Technol. 205 (2011) 4608-4613. doi:10.1016/j.surfcoat.2011.03.140.

[19] N. Bay, Mechanisms Producing Metallic Bonds in Cold Welding, Weld. Reseach Suppl. 62 (1983) 137-142.

[20] S. Bajda, M. Krzyzanowski, K. Muszka, W.M. Rainforth, Numerical analysis of highly reactive interfaces in processing of nanocrystallised multilayered metallic materials by using duplex technique, Surf. Coatings Technol. 277 (2015) 170-180. doi:10.1016/j.surfcoat.2015.07.019.

[21] S. Bajda, D. Svyetlichnyy, D. Retraint, M. Krzyzanowski, Modelling of grain refinement around highly reactive interfaces in processing of nanocrystallised multilayered metallic materials, Int. J. Adv. Manuf. Technol. (2018). doi:https://doi.org/10.1007/s00170-018-1795-2.

[22] M. Eskandari, A. Zarei-Hanzaki, F. Pilehva, H.R. Abedi, S.M. Fatemi-Varzaneh, A.R. Khalesian, Ductility improvement in AZ31 magnesium alloy using constrained compression testing technique, Mater. Sci. Eng. A. 576 (2013) 74-81. doi:10.1016/j.msea.2013.03.050.

[23] M.Z. Quadir, A. Wolz, M. Hoffman, M. Ferry, Influence of processing parameters on the bond toughness of roll-bonded aluminium strip, Scr. Mater. 58 (2008) 959-962. doi:10.1016/j.scriptamat.2008.01.022.

[24] S. Bahl, S. Suwas, T. Ungar, K. Chatterjee, Elucidating microstructural evolution and strengthening mechanisms in nanocrystalline surface induced by surface mechanical attrition treatment of stainless steel, Acta Mater. 122 (2017) 138-151. doi:10.1016/j.actamat.2016.09.041.

[25] P. Hedström, L.E. Lindgren, J. Almer, U. Lienert, J. Bernier, M. Terner, M. Odén, Load partitioning and strain-induced martensite formation during tensile loading of a metastable austenitic stainless steel, Metall. Mater. Trans. A Phys. Metall. Mater. Sci. 40 (2009) 1039-1048. doi:10.1007/s11661-009-9807-3.

[26] K. Spencer, J.D. Embury, K.T. Conlon, M. Véron, Y. Bréchet, Strengthening via the formation of strain-induced martensite in stainless steels, Mater. Sci. Eng. A. 387-389 (2004) 873-881. doi:10.1016/j.msea.2003.11.084.

[27] G. Huang, D. Matlock, G. Krauss, Martensite formation, strain rate sensitivity, and deformation behavior of type 304 stainless steel sheet, Metall. Mater. Trans. A. 20 (1989) 1239-1246. doi:10.1007/BF02647406.

[28] M.B. Picqué, Experimental study and numerical simulation of iron oxide scales mechanical behavior in hot rolling, 2004. https://pastel.archivesouvertes.fr/file/index/docid/500043/filename/these-picque.pdf. 
[29] M.F. Frolish, M. Krzyzanowski, W.M. Rainforth, J.H. Beynon, Oxide scale behaviour on aluminium and steel under hot working conditions, J. Mater. Process. Technol. 177 (2006) 36-40. doi:10.1016/j.jmatprotec.2006.03.224.

[30] D. Kuhlmann-Wilsdorf, Overview No. 131: "regular" deformation bands (DBs) and the leds hypothesis, Acta Mater. 47 (1999) 1697-1712. doi:10.1016/S13596454(98)00413-3.

[31] M.A. Meyers, Y.B. Xu, Q. Xue, M.T. Pérez-Prado, T.R. McNelley, Microstructural evolution in adiabatic shear localization in stainless steel, Acta Mater. 51 (2003) 13071325. doi:10.1016/S1359-6454(02)00526-8.

[32] H. Yang, J.H. Zhang, Y. Xu, M.A. Meyers, Microstructural Characterization of the Shear Bands in Fe-Cr-Ni Single Crystal by EBSD, J. Mater. Sci. Technol. 24 (2008) 819-828.

[33] C.Z. Duan, L.C. Zhang, Adiabatic shear banding in AISI 1045 steel during high speed machining: Mechanisms of microstructural evolution, Mater. Sci. Eng. A. 532 (2012) 111-119. doi:10.1016/j.msea.2011.10.071.

[34] C.S. Lee, W.T. Hui, B.J. Duggan, Macroscopic shear bands in cross-rolled $\alpha$ brass, Scr. Metall. Mater. 24 (1990) 757-762. doi:10.1016/0956-716X(90)90237-B.

[35] S. Ghafari-Gousheh, S. Hossein Nedjad, J. Khalil-Allafi, Tensile properties and interfacial bonding of multi-layered, high-purity titanium strips fabricated by ARB process, J. Mech. Behav. Biomed. Mater. 51 (2015) 147-153. doi:10.1016/j.jmbbm.2015.07.012.

[36] M.R. Barnett, J.J. Jonas, Distinctive Aspects of the Physical Metallurgy of Warm Rolling., ISIJ Int. 39 (1999) 856-873. doi:10.2355/isijinternational.39.856.

[37] K.T. Ramesh, Nanomaterials, 2009. doi:10.1007/978-0-387-09783-1_1.

[38] M. Umemoto, K. Todaka, K. Tsuchiya, Formation of nanocrystalline structure in carbon steels by ball drop and particle impact techniques, Mater. Sci. Eng. A. 375-377 (2004) 899-904. doi:10.1016/j.msea.2003.10.198.

[39] M. Haddad, Y. Ivanisenko, E. Courtois-Manara, H.-J. Fecht, In-situ tensile test of high strength nanocrystalline bainitic steel, Mater. Sci. Eng. A. 620 (2015) 30-35. doi:10.1016/j.msea.2014.09.088.

[40] J. Talonen, H. Hänninen, Formation of shear bands and strain-induced martensite during plastic deformation of metastable austenitic stainless steels, Acta Mater. 55 (2007) 6108-6118. doi:10.1016/j.actamat.2007.07.015.

[41] D. Jia, K.T. Ramesh, E. Ma, Effects of nanocrystalline and ultrafine grain sizes on constitutive behavior and shear bands in iron, Acta Mater. 51 (2003) 3495-3509. doi:10.1016/S1359-6454(03)00169-1.

[42] T.R. Malow, C.C. Koch, Mechanical properties, ductility, and grain size of nanocrystalline iron produced by mechanical attrition, Metall. Mater. Trans. A. 29 (1998) 2285-2295. doi:10.1007/s11661-998-0106-1.

[43] Q. Wei, D. Jia, K.T. Ramesh, E. Ma, Evolution and microstructure of shear bands in nanostructured Fe, Appl. Phys. Lett. 81 (2002) 1240-1242. doi:10.1063/1.1501158.

[44] Q. Wei, L. Kecskes, T. Jiao, K.T. Hartwig, K.T. Ramesh, E. Ma, Adiabatic shear banding in ultrafine-grained Fe processed by severe plastic deformation, Acta Mater. 52 (2004) 1859-1869. doi:10.1016/j.actamat.2003.12.025.

[45] A. Vinogradov, S. Hashimoto, Multiscale phenomena in fatigue of ultra-fine grain materials - An overview, Mater. Trans. 42 (2001) 74-84. doi:10.2320/matertrans.42.74.

[46] F. Lin, Y. Zhang, N. Tao, W. Pantleon, D. Juul Jensen, Effects of heterogeneity on recrystallization kinetics of nanocrystalline copper prepared by dynamic plastic deformation, Acta Mater. 72 (2014) 252-261. doi:10.1016/j.actamat.2014.03.036.

[47] F. Dalla Torre, H. Van Swygenhoven, M. Victoria, Nanocrystalline electrodeposited 
Ni: microstructure and tensile properties, Acta Mater. 50 (2002) 3957-3970. doi:10.1016/S1359-6454(02)00198-2.

[48] J. Xie, X. Wu, Y. Hong, Shear bands at the fatigue crack tip of nanocrystalline nickel, Scr. Mater. 57 (2007) 5-8. doi:10.1016/j.scriptamat.2007.03.027.

[49] N. Tao, H. Zhang, J. Lu, K. Lu, Development of Nanostructures in Metallic Materials with Low Stacking Fault Energies During Surface Mechanical Attrition Treatment (SMAT), Mater. Trans. 44 (2003) 1919-1925. doi:10.2320/matertrans.44.1919.

[50] T. Roland, D. Retraint, K. Lu, J. Lu, Enhanced mechanical behavior of a nanocrystallised stainless steel and its thermal stability, Mater. Sci. Eng. A. 445-446 (2007) 281-288. doi:10.1016/j.msea.2006.09.041.

[51] F. Gauzzi, R. Montanari, G. Principi, M.E. Tata, AISI 304 steel: anomalous evolution of martensitic phase following heat treatments at $400{ }^{\circ} \mathrm{C}$, Mater. Sci. Eng. A. $438-440$ (2006) 202-206. doi:10.1016/j.msea.2006.02.116.

[52] Y.S. Jung, Y.K. Lee, D.K. Matlock, M.C. Mataya, Effect of grain size on straininduced martensitic transformation start temperature in an ultrafine grained metastable austenitic steel, Met. Mater. Int. 17 (2011) 553-556. doi:10.1007/s12540-011-0804-x.

[53] K. Nohara, Y. Ono, N. Ohashi, Composition and Grain Size Dependencies of Straininduced Martensitic Transformation in Metastable Austenitic Stainless Steels, Tetsu-toHagane. 63 (1977) 772-782.

[54] V. Shrinivas, S.K. Varma, L.E. Murr, Deformation-induced martensitic characteristics in 304 and 316 stainless steels during room-temperature rolling, Metall. Mater. Trans. A. 26 (1995) 661-671. doi:10.1007/BF02663916.

[55] S.-J. Lee, Y.-K. Lee, Effect of Austenite Grain Size on Martensitic Transformation of a Low Alloy Steel, Mater. Sci. Forum. 475-479 (2005) 3169-3172. doi:10.4028/www.scientific.net/MSF.475-479.3169.

[56] L. Waltz, D. Retraint, A. Roos, P. Olier, J. Lu, High Strength Nanocrystallized Multilayered Structure Obtained by SMAT and Co-Rolling, Mater. Sci. Forum. 614 (2009) 249-254. doi:10.4028/www.scientific.net/MSF.614.249.

[57] L. Sadok, J. Luksza, J. Majta, Inhomogeneity of mechanical properties in stainless steel rods after drawing, J. Mater. Process. Tech. 44 (1994) 129-141. doi:10.1016/09240136(94)90044-2.

[58] G. Sundararajan, Y. Tirupataiah, The hardness-flow stress correlation in metallic materials, Bull. Mater. Sci. 17 (1994) 747-770. doi:10.1007/BF02757555.

[59] D. Umbrello, R. M'Saoubi, J.C. Outeiro, The influence of Johnson-Cook material constants on finite element simulation of machining of AISI 316L steel, Int. J. Mach. Tools Manuf. 47 (2007) 462-470. doi:10.1016/j.ijmachtools.2006.06.006. 